\title{
Clinical profile of patients with pelvic adnexal masses
}

\author{
Suksham Sharma, Ajay Wakhloo, Gagan Singh*
}

Department of Obstetrics and Gynecology, Government Medical College, Jammu, Jammu and Kashmir, India

Received: 10 September 2018

Accepted: 05 October 2018

\section{*Correspondence: \\ Dr. Gagan Singh, \\ E-mail: gaganbhau@gmail.com}

Copyright: (c) the author(s), publisher and licensee Medip Academy. This is an open-access article distributed under the terms of the Creative Commons Attribution Non-Commercial License, which permits unrestricted non-commercial use, distribution, and reproduction in any medium, provided the original work is properly cited.

\begin{abstract}
Background: Adnexal masses are frequent findings in women of all age groups. It consists of the ovaries, fallopian tubes and uterine ligaments. Women can present with various gynaecological complaints and adnexal masses could be detected while examining and investigating for these complaints. Aim was to study the clinical profile of women in reproductive age group presented with adnexal masses.

Methods: The study comprised of 48 women of reproductive age group. Per speculum examination was done and PAP smear was taken before bimanual examination was done.A complete per vaginum examination was done and the adnexal mass was assessed for its size, side, consistency, laterality and tenderness.

Results: Pain in the lower abdomen was the commonest chief complaint seen in $87.5 \%$ cases. Out of these, majority i.e. $66.67 \%$ had chronic pelvic pain and $23 \%$ had pain of less than 1-month duration which were cases of ectopic pregnancy. $41.67 \%$ cases were suspected to have endometriosis,33.33\% were suspected to have ovarian cyst, followed by ectopic pregnancy in $16.67 \%$ cases and tubo-ovarian mass in $8.33 \%$ cases.

Conclusions: The present study shows that if proper preoperative evaluation is done, we can select the appropriate patients for laparoscopic approach.
\end{abstract}

Keywords: Adnexal masses, Clinical examination, Diagnosis, Reproductive age

\section{INTRODUCTION}

Adnexal masses are frequent findings in women of all age groups. It consists of the ovaries, fallopian tubes and uterine ligaments. Women can present with various gynaecological complaints and adnexal masses could be detected while examining and investigating for these complaints. ${ }^{1}$ The prevalence of adnexal masses is $0.17 \%$ to $5.9 \%$ in asymptomatic and $7.1 \%$ to $12 \%$ in symptomatic patients. ${ }^{2}$ It has been estimated that $5 \%$ to $10 \%$ of women will undergo a surgical procedure owing to a suspected ovarian mass during their lifetime, and $13 \%$ to $21 \%$ of these women will suffer from malignancy. ${ }^{3}$ Clinical diagnosis is based on symptoms like reverse renal colic and palpable mass but it can be challenging if there is torsion of normal adnexa and when pelvic examination is not possible in unmarried women. ${ }^{4}$ Early diagnosis and intervention is essential especially in adolescent girls to conserve the ovarian function. Pregnancy related conditions like ectopic pregnancy and miscarriages are diagnosed easily with a positive pregnancy test and necessary action taken. Ultrasound is the most common initial approach for diagnosis of adnexal mass with Doppler flow to rule out torsion. ${ }^{5}$ The present study was conducted to study the clinical profile of women in reproductive age group presented with adnexal masses.

\section{METHODS}

This prospective study was conducted in the Department of Obstetrics and Gynaecology, Government Medical 
College, Jammu, after taking approval from the Ethical Committee of the Institution. All eligible patients were explained the purpose of the study. A written consent was taken from all the patients before enrolling them in the study. Inclusion criteria was women in reproductive age group, benign nature of adnexal mass on clinical examination and ultrasonographic confirmation of benign nature of the mass. While exclusion was post-menopausal females and girls less than 15 years of age, any evidence of malignancy on clinical or ultrasonographic examination and sign and symptoms of acute abdomen.

Detailed clinical history including chief complaints and their elaboration, parity and obstetrical history, menstrual history, relevant gynaecological history, past history and family history was taken. Complete clinical examination was done. Per speculum examination was done in married women to look for any bleeding or discharge per vagina and status of cervix and vagina. PAP smear was taken before bimanual examination was done. A complete per vagina examination was done and the adnexal mass was assessed for its size, side, consistency, laterality and tenderness. Malignancy was suspected if pelvic mass felt solid, fixed or irregular or if an upper abdominal mass or ascites was also present. Per rectal examination was done in unmarried females.

\section{RESULTS}

The study comprised of 48 patients of reproductive age group. The patient's age in present study varied from 1840 yrs. Maximum number of patients were in the age group 26-30 years i.e., $47.92 \%$ with mean age of $20.08 \pm 5.48$ years. Out of a total number of 48 patients with adnexal masses, 6 were unmarried females and majority of them had endometriosis. The mean parity of patients was $1.15 \pm 1.20$ with a minimum of 0 and maximum of 5. Maximum number of patients i.e. $45.83 \%$ were nulliparous who came to hospital in view of infertility (Table 1).

Table 1: Characteristics of patients.

\begin{tabular}{|lll|}
\hline Characteristics & No. of patients & Percentage \\
\hline Age (years) & & \\
\hline$\leq 20$ & 3 & 6.25 \\
\hline $21-25$ & 10 & 20.83 \\
\hline $26-30$ & 23 & 47.92 \\
\hline $31-35$ & 7 & 14.58 \\
\hline $36-40$ & 5 & 10.42 \\
\hline Marital status & & \\
\hline Unmarried & 42 & 87.50 \\
\hline Married & 6 & 12.50 \\
\hline Parity & & \\
\hline 0 & 22 & 45.83 \\
\hline 1 & 5 & 10.42 \\
\hline 2 & 14 & 29.17 \\
\hline 3 & 6 & 12.50 \\
\hline$\geq 4$ & 1 & 2.08 \\
\hline
\end{tabular}

The most common presenting complaint in present study was pain lower abdomen which was present in $87.50 \%$ of patients. Infertility was the second most common presentation seen in $22.92 \%$ of patients. The next most common complaint was dysmenorrhea (20.83\%). This was followed by amenorrhea (16.67\%) which was seen in patients of ectopic pregnancy. Other less common complaints were dyspareunia, vaginal discharge and fever. Majority i.e. $66.67 \%$ of patients had pain of more than 2 months duration. Most of the patients with less than 1 month duration were cases of ectopic pregnancy (Table 2).

Table 2: Symptoms of the studied population.

\begin{tabular}{|lll|}
\hline Symptoms & No. of patients $(\mathbf{n = 4 8})$ & Percentage \\
\hline Pain & 42 & 87.50 \\
\hline Infertility & 11 & 22.92 \\
\hline Amenorrhea & 8 & 16.67 \\
\hline Dyspareunia & 3 & 6.25 \\
\hline Dysmenorrhea & 10 & 20.83 \\
\hline Menorrhagia & 1 & 2.08 \\
\hline Fever & 1 & 2.08 \\
\hline Discharge P/V & 1 & 2.08 \\
\hline
\end{tabular}

Twenty-two patients had normal cytology while twelve had inflammatory cytology. Patients with inflammatory cytology were given antibiotics (Table 3).

Table 3: PAP smear.

\begin{tabular}{|lll|}
\hline PAP smear & No. of patients $(\mathbf{n = 3 4})$ & Percentage \\
\hline Normal & 22 & 64.71 \\
\hline Inflammatory & 12 & 35.29 \\
\hline Metaplasia & 0 & 0.00 \\
\hline Dysplasia & 0 & 0.00 \\
\hline Carcinoma & 0 & 0.00 \\
\hline
\end{tabular}

Ovarian cyst of 2 women was palpable per abdomen. Both of them were around the size of 14 weeks gravid uterus. A per vaginum examination was done in 42 patients for the assessment of side, size, consistency and tenderness of adnexal mass. However, in 6 unmarried females, instead a per rectal examination was done. Left sided masses were present in $43.75 \%$ cases while in $41.67 \%$ cases, the masses were right sided. Bilateral masses were suspected in 3 patients.

No well-defined mass could be palpated in 4 patients; though vague fullness could be felt. The average size of adnexal mass in present study was $5.44 \pm 0.31 \mathrm{~cm}$. Majority i.e. $72.92 \%$ adnexal masses were between 3-6 $\mathrm{cm}$. Majority $(81.25 \%)$ adnexal masses appeared cystic on clinical examination. $10.42 \%$ adnexal masses appeared to have mixed consistency. No adnexal mass appeared solid. In 4 cases however no well-defined adnexal mass was palpable and only vague fullness could be felt.18.75\% adnexal masses were tender on examination.81.25\% masses appeared non tender on 
clinical examination (Table 4). Maximum patients i.e., 20 $(41.67 \%)$ were suspected to have endometriosis followed by ovarian cyst in $16(33.33 \%)$ patients. $8(16.67 \%)$ patients were provisionally diagnosed to have chronic ectopic pregnancy and another $4(8.33 \%)$ patients were suspected to have TO mass. These patients were subsequently subjected to laparoscopic surgery for confirmation of diagnosis and management accordingly.

Table 4: Clinical characteristics.

\begin{tabular}{|lll|}
\hline Clinical characteristics & No. of patients & Percentage \\
\hline Laterality & & \\
\hline Left & 21 & 43.75 \\
\hline Right & 20 & 41.67 \\
\hline Bilateral & 3 & 6.25 \\
\hline Ill-defined & 4 & 8.33 \\
\hline Size (cm) & & \\
\hline $3-4$ & 18 & 37.50 \\
\hline $5-6$ & 17 & 35.42 \\
\hline $7-8$ & 7 & 14.58 \\
\hline $9-10$ & 1 & 2.08 \\
\hline$>10$ & 1 & 2.08 \\
\hline Ill-defines & 4 & 8.33 \\
\hline Consistency & & \\
\hline Cystic & 39 & 81.25 \\
\hline Solid & 0 & 0.00 \\
\hline Mixed & 5 & 10.42 \\
\hline Fullness & 4 & 8.33 \\
\hline Tenderness & & \\
\hline Tender & 9 & 81.25 \\
\hline Non-tender & 39 & \\
\hline & & 18.75 \\
\hline
\end{tabular}

\section{DISCUSSION}

Maximum number of patients in present study were in the age group of 21-30 years with a mean age of $20.08 \pm 5.48$ years. Patients in present study were younger as we had excluded peri-menopausal and post-menopausal women from present study. Studies limited only to reproductive age women, Barla $\mathrm{J}$ et al (mean age, 28 years), Saito $\mathrm{S}$ et al. (mean age 31 years), shows age distribution similar to present study.

In present study the most common presenting symptom was abdominal pain which was seen in $42(87.5 \%)$ women. Majority of these patients i.e. $28(66.67 \%)$ had pain of more than 2 months duration. Most of them had vague dull aching pain in the lower abdomen. In these patients, endometriosis, ovarian cyst, paraovarian cyst were among the most common final diagnosis made on laparoscopy. In a study by Howard FM,65\% of the women with chronic pelvic pain had at least one pathology detected on laparoscopy while in $35 \%$ cases no pelvic abnormality was seen. ${ }^{8}$ Endometriosis was diagnosed in one-third of laparoscopies while adhesions were diagnosed in about one-quarter of laparoscopies in this study. Pain of less than one-month duration was seen in $10(23 \%)$ patients. Of these, 7 were cases of ectopic pregnancy who presented with severe lower abdominal pain. Out of the remaining three, two were cases of haemorrhagic cyst and one was a patient with a large serous cyst of more than $10 \mathrm{~cm}$.

In present study, 44 i.e. $91.67 \%$ patients were correctly diagnosed to have an adnexal mass on per vaginum and/or per rectal examination. The findings of pelvic examination were confirmed by ultrasound and laparoscopy. In 4 i.e. $8.33 \%$ patients, the adnexal mass could not be palpated accurately, though vague fullness was still felt. Consistency was also evaluated by clinical examination. It was found that $39(81.25 \%)$ masses were cystic while $5(10.42 \%)$ masses appeared to have mixed consistency. The assessment of consistency is an important criterion to rule out malignancy. Tenderness of mass on clinical examination is also important. In present study, 9 (18.75\%) masses were tender on clinical examination. Of the 8 cases of ectopic pregnancy, 7 had positive cervical excitation. Various studies have been done to compare the efficacy of preoperative pelvic examination and its correlation with laparoscopic findings. Cunanan RG et al and Fear RE have found $82.5 \%$ and $74 \%$ correlation. ${ }^{9,10}$ In a study by Gupta $\mathrm{H}$ et al. the sensitivity of clinical examination in diagnosing the pelvic adnexal mass was found to be $43.34 \%$ and specificity was $100 \% .^{11}$

\section{CONCLUSION}

Present study has shown that if proper preoperative evaluation is done, we can select the appropriate patients for laparoscopic approach. On the basis of clinical examination, ultrasound findings and other investigations, the possibility of malignancy can be ruled out.

\section{Funding: No funding sources Conflict of interest: None declared \\ Ethical approval: The study was approved by the Institutional Ethics Committee}

\section{REFERENCES}

1. Brown DL, Dudiak KM, Laing FC. Adnexal masses: US characterization and reporting. Radiol. 2010. ;254(2):342-54.

2. Padilla LA, Radosevich DM, Milad MP. Accuracy of the pelvic examination in detecting adnexal masses. Obstet Gynecol 2000;96(4):593-8.

3. Pejovic T, Nezhat F. Laparoscopic management of adnexal masses: the opportunities and the risks. Ann NY Acad Sci 2001; 943(1):255-68.

4. Terzic MM, Dotlic J, Likic I, Ladjevic N, Brndusic $\mathrm{N}$, Arsenovic N, et al. Current diagnostic approach to patients with adnexal masses: Which tools are relevant in routine praxis? Chin $\mathrm{J}$ Cancer Res 2013;25(1):55-62.

5. Dotlić J, Terzić M, Likić I, Atanacković J, Lađević $\mathrm{N}$. Evaluation of adnexal masses: correlation 
between clinical, ultrasound and histopathological findings. Vojnosanitetski pregled 2011;68(10):861-6.

6. Barla J, Yadav R, Agrawal S, RS S, Shukla S. A study to assess the feasibility and safety of laparoscopy in the management of benign adnexal masses. Ind J Gynaecol Endosc. 2013;10:16-8.

7. Saito S, Kajiyama H, Miwa Y, Mizuno M, Kikkawa F, Tanaka S, Okamoto T. Unexpected ovarian malignancy found after laparoscopic surgery in patients with adnexal masses-a single institutional experience. Nagoya J Med Sci. 2014;76(1-2):83.

8. Howard FM. The role of laparoscopy as a diagnostic tool in chronic pelvic pain.Best Pract Res Clin Obstet Gynaecol. 2000;14(3):467-94.

9. Cunanan RG, Caurey NG, Lippes J. Laparoscopic findings in patients with pelvic pain. Am J Obstet Gynecol 1983;146(5):589-91.
10. Fear RE. Laparoscopy: A valuable aid in gynecologic diagnosis. Obstet Gynecol. 1968; 31(3):297-309.

11. Gupta H, Gupta A, Paul M. Role of Diagnostic Laparoscopy in the Evaluation of Pelvic Adnexal Masses. Int $\mathrm{J}$ Innovative Res Development 2015;4(9).

Cite this article as: Sharma S, Wakhloo A, Singh G. Clinical profile of patients with pelvic adnexal masses. Int J Reprod Contracept Obstet Gynecol 2018;7:4684-7. 